\title{
Leg length and risk of cancer in the Boyd Orr cohort
}

\author{
D J Gunnell, G Davey Smith, J M P Holly, S Frankel
}

Editorial by Albanes

Department of Social Medicine, Canynge Hall, Bristol BS8 2PR D J Gunnell, senior lecturer in epidemiology and public health medicine G Davey Smith, professor of clinical epidemiology

S Frankel,

professor of epidemiology and public health medicine

Division of Surgery, University of Bristol, Bristol Royal Infirmary, Bristol BS2 8HW J M P Holly, professor of clinical sciences

Correspondence to Dr Gunnell d.j.gunnell@ bristol.ac.uk
Height is directly associated with mortality from cancer, ${ }^{1}$ but the explanation for this association is unclear. Whereas adult height is a marker of nutrition and health throughout childhood, most growth before puberty is due to increases in leg length. Leg length can therefore be used as a marker for exposures that generate the association between adult height and cancer. ${ }^{2}$ We examined the association between prepubertal leg length and mortality from cancer in the Boyd Orr cohort. ${ }^{23}$

\section{Subjects, methods, and results}

As childhood height is affected by the timing of puberty we restricted our analysis to study members who were aged 2-8 years when their height and leg length were measured. In all, 1167 of these 1392 subjects $(84 \%)$ were traced and had information on childhood and adult socioeconomic status, and they form the basis of this analysis. Using Cox's proportional hazards models we examined mortality from cancer between 1948 and 1997 in relation to internally derived z scores for childhood leg length. ${ }^{2}$ All traced subjects were included in these models up to the time of their death or emigration. To adjust for possible genetic factors associated with overall stature all models also include a term for trunk length $\mathrm{z}$ score. The $\mathrm{z}$ score (standard deviation score) expresses a child's measurement as the number of standard deviations its value is from the mean for its age and sex. In these analyses each unit of the $\mathrm{z}$ score is approximately equivalent to 3-4 $\mathrm{mm}$ (the standard deviation for leg length in these children).

We classed cancers as related to smoking (codes $140,141,143-9,150,157,160-3,188-9$ of the international classification of diseases, ninth revision (ICD-9)) and not related to smoking (all other malignant neoplasms, but mainly colorectal, breast, and ovarian cancers). We further divided cancers unrelated to smoking into sex hormone dependent (174 (breast), 179 (uterus), 182-7 (ovary, prostate, and other genital organs)) and non-sex hormone dependent (all other cancers unrelated to smoking).

The analysis showed a significant positive association between childhood leg length and mortality from cancers unrelated to smoking (table). The observed association was most obvious for mortality from sex hormone dependent cancers-the risk of death increased by $129 \%$ (95\% confidence interval $9 \%$ to $383 \%$ ) for every unit increase in z score for leg length. No significant associations were seen in relation to trunk length (hazard ratio for cancers unrelated to smoking 0.84 (0.58 to 1.22$)$ ), and the associations for overall height were in a similar direction but weaker than those for leg length. There was no association with all cause mortality.

\section{Comment}

In the literature associations between height and cancer have been most consistently shown for breast and prostate cancer, both of which may be hormonally dependent. In line with this, the associations reported here are strongest in relation to sex hormone dependent cancers. Two possible mechanisms may underlie these associations. Firstly, more rapid growth is associated with an earlier puberty and therefore a longer exposure to adult concentrations of sex hormones. Secondly, childhood diet may influence concentrations of insulin-like growth factor-I, ${ }^{4}$ subsequent growth (as indexed by childhood leg length), ${ }^{2}$ and later risk of cancer. ${ }^{3}$ Insulin-like growth factor-I may increase the risk of cancer through several mechanisms, including protecting genetically damaged cells from apoptosis (cell suicide), stimulating cell proliferation, and amplifying the production of sex hormones by gonadotrophins. ${ }^{4}$ A role of insulin-like growth factor-I in cancer development is further supported by the results of recent prospective studies showing its strong association with risk of breast and prostate cancer. ${ }^{4}$ In one study the associations were independent of sex hormone concentrations. ${ }^{5}$ Future studies should deter-

\begin{tabular}{|c|c|c|c|c|c|}
\hline Cause of death & No of deaths & $\begin{array}{c}\text { Adjusted hazard ratio } \\
(95 \% \mathrm{Cl}) \dagger\end{array}$ & $\begin{array}{l}P \text { value for } \\
\text { linear trend }\end{array}$ & $\begin{array}{l}\text { Adjusted hazard ratio } \\
(95 \% \mathrm{CI}) \ddagger\end{array}$ & $\begin{array}{l}P \text { value for } \\
\text { linear trend }\end{array}$ \\
\hline All causes & 174 & 0.96 (0.80 to 1.16$)$ & 0.69 & 1.00 (0.83 to 1.21) & 0.98 \\
\hline \multicolumn{6}{|l|}{ Cancer: } \\
\hline All cancers\| & 53 & 1.37 (0.94 to 1.99$)$ & 0.10 & $1.43(0.97$ to 2.10$)$ & 0.07 \\
\hline Related to smoking§ & 24 & 1.02 (0.62 to 1.68$)$ & 0.93 & 1.08 (0.66 to 1.78 ) & 0.75 \\
\hline Not related to smoking & 29 & 1.74 (1.04 to 2.93$)$ & 0.04 & 1.78 (1.02 to 3.01$)$ & 0.04 \\
\hline Not dependent on sex hormones & 17 & $1.38(0.70 \text { to } 2.75)^{\star *}$ & 0.35 & 1.47 (0.71 to 3.01$)$ & 0.30 \\
\hline Dependent on sex hormonest† & 12 & 2.29 (1.09 to 4.83$)$ & 0.03 & 2.26 (0.99 to 5.16$)$ & 0.05 \\
\hline \multicolumn{6}{|c|}{ 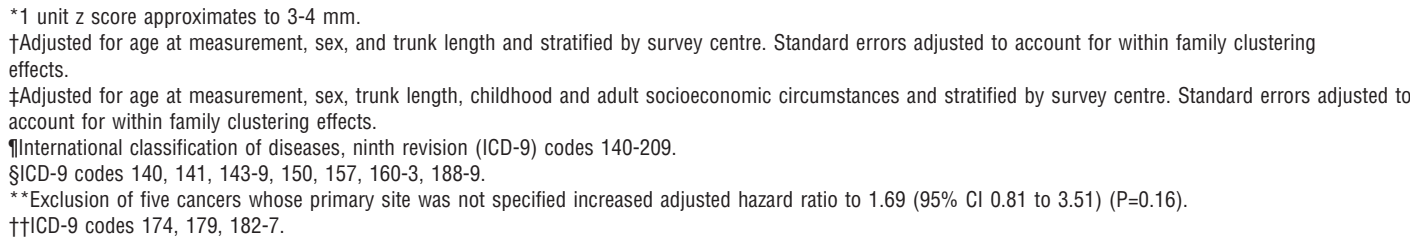 } \\
\hline
\end{tabular}


mine whether growth hormones are as important in the aetiology of human cancer as they are in animal experiments.

We thank Professor Philip James, director of the Rowett Research Institute, for the use of the archive and in particular Walter Duncan, honorary archivist to the institute, for his help. We also thank the staff at the NHS Central Register at Southport and Edinburgh; Sara Bright, Sue Williams, Andrea Wilson, Jenny Eachus, and Sarah Pike for data entry; Tim Peters, Fiona Braddon, Sara Brookes, Phil Chan, and Martin Kemp for technical help; and Dr David Smith for helping us to contact surviving members of the survey teams and for access to his interviews with some of these people. We also acknowledge all the research workers and subjects who participated in the original survey in 1937-9. In particular, we thank Professor J Pemberton, Mrs I Crichton, and the late David Lubbock for information on the design and conduct of the original survey.

Contributors: The Boyd Orr cohort was established by GDS and SF. DJG further developed and refined the cohort. GDS and DJG initiated this reanalysis, and the analyses presented here were performed by DJG. JMPH provided input on the possible role of growth factors in the observed associations. DJG wrote the first draft of the paper and GDS, SF, and JMPH all commented and helped in redrafting the text. DJG, GDS, and SF are guarantors for the study.

Funding: Research on the Boyd Orr cohort was funded by the World Cancer Research Fund, British Heart Foundation, and the Medical Research Council.

Conflict of interest: None.

1 Albanes D, Jones DY, Schatzkin A, Micozzi MS, Taylor PR. Adult stature and risk of cancer Cancer Res 1988;48:1658-62.

2 Gunnell DJ, Davey Smith G, Frankel S, Nanchahal K, Braddon FEM, Pemberton J, et al. Childhood leg length and adult mortality: follow up of the Carnegie (Boyd Orr) Survey of Diet and Health in Pre-War Britain. $J$ Epidemiol Community Health 1998;52:142-52.

3 Frankel S, Gunnell DJ, Peters TJ, Maynard M, Davey Smith G. Childhood energy intake and adult mortality from cancer: the Boyd Orr cohort. BMJ 1998;316:499-504

4 Holly JMP. Insulin-like growth factor-I and new opportunities for cancer prevention. Lancet 1998;351:1373-4.

5 Chan JM, Stampfer MJ, Giovannucci E, Gann PH, Ma J, Wilkinson P, et al. Plasma insulin-like growth factor-I and prostate cancer risk: a prospective study. Science 1998;279:563-6.

(Accepted 28 July 1998)

\title{
Height and mortality from cancer among men: prospective observational study
}

\author{
George Davey Smith, Martin Shipley, David A Leon
}

Experiments in animals have shown that energy intake during the growth period is positively associated with the later incidence of cancer. ${ }^{1}$ Recently, direct evidence of an association between childhood energy intake and adult mortality from cancer among humans was published in a report from the Boyd Orr cohort study. ${ }^{2}$ Childhood energy intake was positively associated with mortality from cancers not related to smoking, whereas there was no association between energy intake and mortality from cancers related to smoking. ${ }^{2}$ This is to be expected as the substantial effects of tobacco would mask any effects of childhood diet on cancers related to smoking.

Height has been used in previous studies as a marker for energy intake in childhood, ${ }^{3}$ with the limited evidence indicating a positive association for some cancer sites. ${ }^{345}$ In the Boyd Orr study data were not available on smoking behaviour and were limited on adulthood socioeconomic position. ${ }^{2}$ We therefore analysed the association between height and mortality from cancer in a large cohort of men for whom detailed data on socioeconomic position in adulthood and on smoking behaviour were available.

\section{Subjects, methods, and results}

In the Whitehall study of London civil servants, data on employment grade, height, and smoking behaviour were available for 17378 men aged 40-64 who were examined between 1967 and 1969. During follow up until 31 January 1995, 2226 of these men died of cancer: 725 from cancers unrelated to smoking and 1501 from cancers related to smoking. To adjust for the potential confounding effects of other variables proportional hazards analyses were carried out with height as a continuous variable and age (in age bands of five years), employment grade (administrative, professional and executive, clerical, other), and smoking behaviour (cigarette smoker, pipe or cigar smoker, ex-cigarette smoker, and number of cigarettes smoked per day for current cigarette smokers) as covariates.

The table shows relative death rates from cancer by height category and for each increment of 6 inches in height (1 inch is about $2.5 \mathrm{~cm}$ ). For cancers unrelated to smoking the association with height was positive and strengthened by adjustment for socioeconomic position (indexed by employment grade) and smoking behaviour. For cancers related to smoking the association between height and mortality was negative but not significant. Adjustment for socioeconomic position and smoking behaviour reversed the direction of the association, but it remained small and non-significant. As expected, cigarette smoking was strongly associated with cancers classified as smoking related but not with cancers classified as unrelated to smoking. The age adjusted relative rates for height and the smoking unrelated and smoking related cancers were significantly different $(\mathrm{P}=0.002)$. Exclusion of mortality occurring during the first five or first ten years of follow up did not materially alter these findings.

Editorial by Albanes

Department of Social Medicine, Canynge Hall, Bristol BS8 2PR

George Davey

Smith,

professor of clinical epidemiology

Department of Epidemiology and Public Health, University College London, London WC1E 6BT

Martin Shipley, senior lecturer in medical statistics

Department of Epidemiology and Population Health, London School of Hygiene and Tropical Medicine, London

WC1E 7HT

David A Leon, reader in

epidemiology

Correspondence to: Professor Davey

Smith

zetkin@bristol.ac.uk

BMJ 1998;317:1351-2

\section{Comment}

Our findings parallel those relating childhood energy intake to cancer mortality in the Boyd Orr cohort 